\title{
Potencialidades que ofrece la peculiar inteligencia emocional de los millennials
}

Potentials offered by the peculiar emotional intelligence of the millennials

\section{Eva Aide Torres Ortega ${ }^{1}$, Cristina Cabrera Ramos ${ }^{2}$, Carlos Cristian de la Rosa Flores ${ }^{3}$, Carmen Romelia Flores Morales ${ }^{4}$}

1(eatorres@uach.mx), Maestra en finanzas, catedrática de la Facultad de Contaduría y Administración de la Universidad Autónoma de Chihuahua. https://orcid.org/0000-0002-0170-446X

2(ccabrera@uach.mx), Maestra en impuestos, catedrática de la Facultad de Contaduría y Administración de la Universidad Autónoma de Chihuahua. https://orcid.org/0000-0002-5789-8427

3 (cdelarosa@uach.mx), Maestro en finanzas, catedrático de la Facultad de Contaduría y Administración de la Universidad Autónoma de Chihuahua. https://orcid.org/0000-0001-8278-5283

4(rmeflore@hotmail.com), Doctora en administración, catedrática investigadora de la Facultad de Contaduría y Administración de la Universidad Autónoma de Chihuahua. https://orcid.org/0000-0002-7220-2504

Eva Aide Torres Ortega

eatorres@uach.mx

Dol https://doi.org/10.46589/rdiasf.vi35.362

Recibido 20 de febrero 2021

Aceptado 17 de mayo 2021

Publicado 30 de junio 2020.

\section{Resumen}

La inteligencia emocional de la generación millennial fue descrita a partir de las cinco competencias que circunscribe la misma definición, según Daniel Goleman. Para lo anterior fue significativo citar diferentes conceptos sobre esta cohorte y delimitar sus particularidades. Se enumeran las características que publicaron, cronológicamente, tres populares autores y se interrelacionaron con las aptitudes de autoconocimiento, autocontrol, motivación, empatía y habilidades sociales que se vinculan a la inteligencia emocional. Aunque se concluyó que los millennials son mayormente diestros controlando sus sentimientos fue recomendable que las instituciones laborales y educativas se involucren activamente llenando los vacíos, en los atributos de empatía y autorregulación, de esta generación para obtener los mayores beneficios para la sociedad.

Palabras clave: inteligencia emocional, millennials, convivencia 


\section{Abstract}

The emotional intelligence of the millennial generation was described from the five competencies that circumscribe the same definition, according to Daniel Goleman. For the above it was significant to cite different concepts about this cohort and define its particularities. The characteristics published, chronologically, by three popular authors were listed and interrelated with the skills of self-knowledge, selfcontrol, motivation, empathy and social skills that are linked to emotional intelligence. Although it was concluded that millennials are mostly skilled at controlling their feelings, it was recommended that labor and educational institutions be actively involved in filling the gaps, in the attributes of empathy and selfregulation, of this generation to obtain the greatest benefits for society

Key words: emotional intelligence, millennials, communal living.

\section{Introducción}

Cansada de las opresiones emocionales, de las fuertes cargas de responsabilidad y la falta de libertad entre otras circunstancias, la generación baby boomer decide heredar un estilo de vida diferente a sus hijos como manumisión al autoritarismo en el que vivió. Debido a esto, ella educó a su descendencia, la generación millennial (1980 -2004), fomentando su seguridad, amor, libertad emocional y su autoestima haciéndola sentirse especial y única, sin embargo, a pesar de sus esfuerzos las aportaciones de Carro (2018), basadas en los estudios de la Asociación Americana de Psicología, puntuan que esta cohorte muestra una mayor tasa de depresión en comparación a las anteriores generaciones, ella tiene mayores dificultades laborales y no sabe como hacer frente a los problemas y al fracaso.

Por otro lado, en el año de 1990 se publica el artículo académico denominado La Inteligencia Emocional, de los autores Salovey y Mayer, y este constituye la inspiración para los vastos estudios sobre este término, en él se evidencia la relación de que el dominio de ciertas habilidades, para la expresión correcta y regulación efectiva de las emociones y sentimientos, favorece el alcance de una vida próspera. Aunque la difusión, comprensión y aceptación de esta innovadora y asertiva teoría fue popular, los jóvenes millennials de hoy son llamados también la "generación triste" o la "generación deprimida", ciertamente por no saber regular de forma eficaz sus emociones y sentimientos. 
La presente globalización, interrelaciona a todos los seres humanos de forma laboral, cultural y/o social, por lo que obliga a compartir responsabilidades y a encontrar soluciones en los vacíos de la educación parental heredada a estos jóvenes.

Debido a todo lo anterior es útil delimitar a la generación y analizar las características que se han mencionado para describirlos. Por lo que el objetivo principal de este estudio es Identificar las competencias que poseen los millennials en relación a la Inteligencia emocional. Para lo anterior se interrelacionan sus peculiaridades con las cinco habilidades que se atribuyen a una inteligencia emocional sana, según Goleman, éstas son el autoconocimeinto, el autocontrol, la motivación, la empatía y las habilidades sociales.

Es transcendental que las Instituciones laborales y educativas estén preparadas en aprovechar las favorables características que desarrollaron los millennials debido a su formación y a la era digital que les influye y así mismo deben de contribuir a fortalecer las competencias endebles que les identifican, ya que esta generación hoy por hoy ocupa puestos profesionales y espacios en las aulas universitarias.

\section{Material y Método}

Para el desarrollo de este estudio se utilizaron los siguientes criterios metodológicos: la naturaleza fue cualitativa, el tipo de la investigación fue básica, el alcance fue descriptivo, el modo fue documental, el diseño fue no experimental-transeccional.

Con el fin de dar cumplimiento al objetivo de este estudio de buscaron tres autores significativos con publicaciones y/o investigaciones referentes a la generación millennial. Por lo anterior, se consideraron los siguientes: N. Howe y W. Strauss fueron los pioneros en el término con su libro Millennials rising: The next great generation, ellos cuentan según datos de la plataforma Google Académico con 6,205 citas y una estadística de búsqueda según la plataforma de Google Trend de 929 (Google, 2021), los parámetros de búsqueda fueron para la zona geográfica en todo el mundo y para el tiempo desde el año 2004, ya que es el año máximo en el que esta plataforma arroja datos. Además, se contempló al autor J. Stein que cuenta con 505 citas para su artículo The me me me Generation, y una estadística en Google trend 432, con los mismos parámetros de búsqueda que el anterior. La tercera autora fue J. Twenge por su libro Generationme, ella cuenta con 3,034 citas y una estadística de búsqueda de 382 por el mismo periodo que los anteriores y una zona geográfica mundial. 
Se realizó un cuadro comparativo de acuerdo a las sólidas y endebles características descritas por estos tres autores dentro de las cinco competencias que según Daniel Goleman circunscriben una favorable inteligencia emocional.

\section{Resultados}

\subsection{Aproximación conceptual de la generación millennials}

El término millennials surge a raíz la publicación del libro Generations: The History of America's Future, 1584 to 2069 donde los autores Howe y Strauss (1987) mencionan que la generación nacida después del año 1982 será la primera en alcanzar la mayoría de edad en el año 2000; esta generación, agregan además es más lista, mejor portada y con mejor espíritu cívico.

Para consolidar el término millennials en el libro Millennials Rising (2000), Howe y Strauss mencionan que el sondeo realizado por Peter Jennings a través de $A B C$ World News Tonight, el 19 de diciembre de 1997, el calificativo mayormente favorecido para nombrar esta generación, dentro de otros diez, fue millennials. El resto de los nombres fueron: "No nos etiqueten", "Generación Y (o por qué)", "Generación Tec”, "Generación Next”, "Generación.com”, "Generación 2000", "Echo Boom", "Boomer Babies" y "Generación XX".

La definición que otorga al vocablo en cuestión el diccionario de Cambridge University Press (2019) puntúa que son las "personas que han nacido en los '80, '90 o cerca de los 2000, han crecido con el internet y no se pueden imaginar el mundo sin él" (p.1).

En el mismo libro, Millennials Rising se amplía el concepto de esta cohorte como sigue:

Son nacidos entre los años 1982 y 2004, los millennials son diferentes a cualquier otra generación que se recuerde. Son más numerosos, más pudientes, mejor educados, étnicamente más diversos. Lo más importante es que manifiestan hábitos sociales más positivos como el trabajo en equipo, buena conducta, modestia y realización. En los próximos años la generación del milenio reformulará la imagen de los jóvenes desde las características endebles hasta las sólidas generando cambios sísmicos en toda América. Al analizar estos cambios característicos en esta generación comparados con otras anteriores, se puede prever como, en su transición a la vida adulta, llegarán al poder. Los millennials son la generación dominante de la tecnología y se aprecia con facilidad que serán la siguiente Gran generación de Estados Unidos. (Howe y Strauss, 2000, p. 12 y 13) 
En el mismo sentido Pérez, (2019) indica que:

Se llama millennial a cada miembro de la Generación del Milenio o Generación Y, un grupo que integra a las personas nacidas entre el comienzo de la década de 1980 y el inicio de la década de 2000. Los millennials, de acuerdo a los sociólogos, comparten determinadas características más allá de las diferencias individuales y culturales. (p.1)

Por su parte Ruíz, (2017) define a la generación millennial como:

La cohorte de personas nacidas entre los años 1981 y 2000. Bennett, Maton, Kervin, Wesner y Miller (como se citó en Ruíz, 2017) señalan que ésta generación es la primera que ha pasado toda la vida en un entorno digital, un hecho que ha condicionado sus valores, su trabajo y la forma de relacionarse con el mundo. Los millennials son considerados hijos de la generación Baby Boomer y los acontecimientos de su infancia fueron la globalización, los ataques del 11 de septiembre y la era del Internet. (p.350)

Por el contrario de Strauss y Howe, Twenge, (2006), asegura en su libro Generation Me que los millennials son:

Los nacidos en los 80's y 90's; también pueden ser llamados "la Generación de Engreídos" o "La Generación del Yo", ellos se caracterizan por ser seguros, de amplio criterio, ambiciosos; pero también narcisistas, indiferentes, desconfiados y ansiosos. Esta generación está reestructurando las escuelas, los colegios, y los negocios en todo el país. Son los hijos de la generación de Baby Boomers, y no solo están resintiendo los efectos de la recesión y cambiando el mercado laboral, ellos están afectando el cambio en todo el mundo. Ellos están redefiniendo lo que significa ser un individuo en la sociedad de hoy. (p.1)

Concordando con Twenge, Stain (2013) en su artículo Millennials: The Me Me Me Generation describe a esta legión de jóvenes como:

Los nacidos entre los años 1980 y 2000. Los millennials hoy en día son muy similares en todo el mundo, gracias a la globalización y a las redes sociales; a diferencia de la similitud 
que tuvieron generaciones anteriores dentro de sus propias naciones. $Y$ estas características no son exclusivas de los millennials de altos estratos sociales, millennials de bajo nivel social muestran incluso más altas tasas de narcisismo, materialismo y adicción a la tecnología. Los millennials son perezosos, engreídos, egoístas y superficiales. (p.1)

En base a lo anterior se considera millennials a la cohorte de individuos nacidos entre los años de 1980 y 2004, descendientes de la generación baby bommers, quienes habiendo crecido inmersos en un mundo globalizado y en entornos sumamente digitales comparten características cualitativas similares a nivel internacional. Debido a lo anterior son disímiles a cualquier generación anterior. La educación que recibieron de los baby boomers, las ventajas tecnológicas con las que crecieron, así como los eventos históricos que les influyeron, generaron en ellos contrastantes cualidades tales como ser mejor educados, más seguros de sí mismos, tener hábitos sociales más positivos como el trabajo en equipo, más listos, más amplio criterio, ambiciosos, tener más amplio criterio y espíritu de realización; pero también son narcisistas, materialistas, engreídos, indiferentes, desconfiados y ansiosos. Esta generación está revolucionando ámbitos culturales, económicos, laborales y educacionales, entre otros.

\subsection{Caracterización de la generación millennials}

Se enlistan las características generacionales de esta cohorte, que definen los tres autores citados, de acuerdo a su órden cronológico de publicación:

Howe y Strauss (2000), (como se cita en Monaco y Martin, 2007) resumen las siete características de los estudiantes millennials:

1. Los millennials sienten que son especiales. Una llave clave que contribuye a este sentimiento es la fuerte relación que los millennials tienen con sus padres. Los padres de los millennials están más involucrados con los estudiantes de universidad y desean ser parte de su vida universitaria.

2. Esta generación ha sido sobreprotegida. Los millennials son considerados como el movimiento de seguridad juvenil más radical en la historia de América. Letreros de "bebé a bordo" y cerrojos de seguridad para niños, ejemplifican a esta generación creciendo con la seguridad como prioridad. Como resultado, estos jóvenes esperan reglas con las respectivas consecuencias. Padres encargados de reglamentar el horario de sus hijos con actividades 
extras han disminuido la oportunidad de pensamientos creativos independientes y habilidades en la toma de decisiones lo que aporta un reto a los patrones y educadores de esta generación.

3. Ellos prefieren el trabajo en equipo. Se sienten menos cómodos trabajando de forma individual. El trabajo independiente tiene un mayor grado de fracaso por lo tanto les disgusta trabajar solos. Consecuentemente prefieren trabajar cooperativamente en grupos.

4. Esta cohorte es segura y altamente optimista. Los millennials tienen grandes sueños y expectativas sin tener claro el camino para alcanzar el éxito, pero están seguros de que lo lograrán. Ellos tienen un compromiso muy modesto con sus obligaciones y se frustran rápidamente si no alcanzan sus metas. Su habilidad para realizar múltiples quehaceres con tecnología fortalece su seguridad. Ellos tienen acceso a la información a través del internet las 24 horas del día, los 7 días de la semana de forma instantánea; por lo que esto conlleva a que deseen respuestas inmediatas. Los correos electrónicos los consideran obsoletos debido a la demora de respuesta. Mensajes de texto o instantáneos proveen la celeridad que ansían. Ellos han sido tecnológicamente estimulados en su infancia y demandan esta conectividad de forma regular.

5. Los millennials se sienten presionados. Está generación se siente presionada para actuar ante aquellos que serán sus jueces, por esto mismo ellos anhelan retroalimentación. Ellos prosperan con comentarios positivos, así mismo se paralizan sin retroalimentación ni dirección.

6. Tienen un fuerte deseo de logro. Esto apoya la primera característica de Howe y Strauss, de sentirse únicos. Durante su infancia los millennials fueron convencidos de que eran especiales y que podría lograr grandes metas. De hecho, algunos autores aseguran que son la siguiente "grandiosa generación".

7. Son convencionales. Ellos respetan y aceptan una gran variedad de diferencias socioculturales. Esta generación es caracterizada por ser pacifista a diferencia de la generación $\mathrm{X}$, que le precede, que se considera rebelde.

Contradictoriamente a las anteriores positivas ventajas que califican a los millennials, Twenge, (2006) caracteriza a la generación Millennial como tolerantes, confiados, de mentalidad abierta y ambiciosos, pero también como desconectados, narcisistas, desconfiados y ansiosos.

- Son los hijos de la generación Baby Boomers y ellos están afectando el cambio en todo el mundo. 
- Para la Generación Me o Millennials la manera de vestirse es una forma de auto-expresarse, ellos eligen lo que cómodamente les complace, a diferencia de generaciones anteriores cuya educación incluía reglas estrictas de etiqueta en la formalidad de la vestimenta. Aún existen pocos lugares de trabajo donde es requisito acudir vestidos apropiadamente.

- En Generaciones anteriores los deberes y las responsabilidades eran mucho más importantes que las necesidades y deseos individuales, se hacían ciertas cosas, se decían ciertas cosas, no se hablaba de ciertas cosas y fin de la historia. Hoy en día poco de esto aplica, los individuos se guían por sus necesidades y deseos personales. Hoy se sugiere seguir sueños y perseguir la felicidad por encima de todo. Se permite ser diferente y escoger lo que sea mejor para cada quien.

- El consejo más común dado a los jóvenes es "sé tú mismo".

- Las tendencias sociales, que más bien son una revolución, se pueden atar a las frases: "haz lo que te haga feliz y no te preocupes por lo que otros piensan". Esto es enormemente diferente a las filosofías de las décadas anteriores.

- Esta generación ha sido influenciada por una serie de filmografías basadas en la idea de revelarse a las normas sociales restrictivas, hacer lo que te haga feliz, provocando la caída de las reglas sociales y alzando el individualismo.

- Las publicaciones editoriales, así mismo, favorecen las ideologías sobre el individualismo y la búsqueda de la felicidad propia sin importar lo que otros digan o piensen, completamente contrario a la educación que recibieron los Baby Boomers.

- Los dos términos más populares para describir a los jóvenes de esta generación son: "independientes" y "mente abierta".

- La mentalidad de los millennicos sobre la moralidad se refiere como que es un asunto de opinión personal, cada quién debe de preocuparse por sí mismo, sin meterse en la vida de los demás.

- Una ventaja de la actitud individualista es la reducción de prejuicios y discriminación, ellos entienden que "ser diferente es bueno", son tolerantes a las razas, creencias, sentimientos, religiones y orientaciones sexuales. La Generación Me es la generación más tolerante de la historia de América, con los únicos que no son tolerantes son con los intolerantes. 
- Los jóvenes hoy se dirigen de igual forma a los adultos y figuras de autoridades, que a sus amigos, no saben hablar formalmente y sin majaderías cuando es necesario.

- Esta generación piensa que los fines justifican los medios, hacer trampa o usar acordeón en un examen no es tan malo ni tampoco tan raramente usado. Esto es una ruptura en los valores de consideración y lealtad. Los escándalos financiaros actuales han demostrado que la gente, hoy por hoy, no tiene ningún problema en romper las reglas y contar mentiras en el intento de hacer dinero.

- GenMe no solo cuestiona la autoridad, ellos la ignoran completamente. Los jóvenes que integran esta generación no reconocen líneas de subordinación ante autoridades, tales como maestros o jefes de trabajo, lo que demuestra una gran autoestima y seguridad en ellos,pero también conflictos en la falta de respeto al prójimo o normas. Los padres de los millennials han contribuido a esta situación, ellos no quieren ser la autoridad de sus hijos, ellos quieren ser sus amigos, lo que significa también que tienen un rol más amplio en las decisiones familiares.

Adicionalmente Stein, (2013) argumenta contar con evidencias al respecto de los atributos de esta generación de acuerdo a lo siguiente:

- El desorden de personalidad narcisista es tres veces más alto para esta generación, ella muestra conflictos al aceptar opiniones diferentes a las suyas.

- Los millennials creen que deben de ser ascendidos de puesto cada dos años sin importar su desempeño.

- Ellos crecieron sin la necesidad de utilizar las matemáticas mentales gracias a las computadoras.

- Las particularidades de los millennials son parcialmente consecuencia de que en los años 70 la sociedad deseaba favorecer las probabilidades de triunfo de sus hijos, fortaleciendo su autoestima; sin embargo, resultó que la autoestima fue buena para conseguir un trabajo o una pareja en un bar, pero no para mantener ni el trabajo ni las relaciones emocionales a largo plazo. El problema generado fue que, por tratar de aumentar la seguridad, incrementaron accidentalmente el egocentrismo. 
- Toda esa autoestima se convierte en decepción cuando el mundo se rehúsa a confirmar lo grandes que ellos crecieron pensando que eran. Esta generación tiene las más altas probabilidades de tener expectativas insatisfechas con sus carreras profesionales. Tienen un miedo enorme al fracaso.

- Su desarrollo fue atrofiado prolongando la etapa de la vida que va de la adolescencia a la adultez; más individuos entre los 18 y 29 años de edad solían vivir con sus padres en lugar de con sus cónyuges, según una encuesta de Clark University de 2012.

- Los millennials socializan utilizando mensajes de texto con sus celulares en promedio 88 veces al día, lo que hace que tengan una influencia más que considerable de sus amigos. Nunca antes en la historia los jóvenes habían llegado a la edad de 23 años tan dominados por sus amigos, los adolescentes no podrán prosperar si no se relacionan con gente madura.

- Ellos han buscado constantemente la dopamina que les produce el saber que a alguien le gustó la actualización del estado en sus redes sociales. Investigaciones muestran que a partir del año 2000 las puntuaciones de empatía cayeron bruscamente, quizá por la falta de vínculos generados de la convivencia cara a cara.

- Los millennials retrasan decisiones trascendentales debido a que hoy por hoy las opciones a su alcance son innumerables en todos los ámbitos, carreras profesionales que antes no existían, matrimonios con personas de cualquier parte del mundo que pueden conocer a través de las redes sociales, en lugar de únicamente del salón de clases; buscan nuevas, mejores y más experiencias.

- Los millennials tienen vastas habilidades para negociar mejores contratos con las instituciones tradicionales.

- Las generaciones anteriores solían solo "hacer" sus deberes, los millennials piensan y luego hacen sus obligaciones.

- Ellos son optimistas, idealistas, pragmáticos, soñadores. Son espontáneos, reservados y no tan apasionados.

- Son capaces de aceptar las diferencias entre homosexuales, mujeres y cualquier minoría internacionalmente.

- La nueva mentalidad de la generación es innovar mejores formas de hacer las cosas. 


\subsection{La inteligencia emocional}

Aunque el origen del término Inteligencia emocional se le atribuye a Wayne Payne (1985), éste se popularizo gracias a la obra de Daniel Goleman, publicada en 1995. Por lo anterior el análisis de este estudio está cimentado en la obra citada. Según Goleman (1995):

La inteligencia emocional nos permite tomar conciencia de nuestras emociones, comprender los sentimientos de los demás, tolerar las presiones y frustraciones que soportamos en el trabajo, acentuar nuestra capacidad de trabajar en equipo y adoptar una actitud empática y social, que nos brindará mayores posibilidades de desarrollo personal. (p.3)

Esta aptitud implica entonces, saber dotar de inteligencia a la emoción para dominar decisiones precipitadas y transformar positivamente los resultados que se pretenden obtener.

Son los sentimientos los que provocan impulsos para actuar y permiten salir avante en las adversidades, todos poseen un bagaje emocional con un incalculable valor de supervivencia. El hacer y decir obedece tanto, y a veces más, a los sentimientos y a las ideologías personales.

Aunque ciertos expertos aseguran que el coeficiente intelectual $(\mathrm{Cl})$ es un dato genético que no puede ser modificado Goleman asevera, en su libro, que el $\mathrm{Cl}$ no es determinante para el éxito y/o fracaso de un individuo en sus planes de vida; ya que existen habilidades que se desarrollan con las experiencias de vida, familiares o educativas por ejemplo, habilidades entre las que destacan el autocontrol, el entusiasmo, la perseverancia, la capacidad para motivarse a sí mismo y el altruismo que reside en la empatía. Éstas son las características que conforman la Inteligencia Emocional ya que son el lazo entre los sentimientos, el carácter y los impulsos morales que provocan las decisiones y/o acciones de cualquier individuo.

La competencia emocional constituye, en suma, una meta-habilidad que determina el grado de pericia que lograremos en el dominio de todas nuestras otras facultades. Salovey (como se cita en Goleman, 1985) enumera a las inteligencias personales de Gardner y las organiza hasta abarcar cinco competencias principales:

1. Autoconocimiento. El conocimiento de las propias emociones, es decir la capacidad de reconocer un sentimiento en el mismo momento en que aparece resulta crítico para la autocomprensión y la introvisión psicológica, al contrario; la inhabilidad de identificarlo deteriora el control para dirigir la vida. 
2. Autocontrol. Es la capacidad de controlar los impulsos emocionales, es tener tolerancia, voluntad y carácter ante presiones y frustraciones. La habilidad que permite controlar los sentimientos ante las vicisitudes de la vida y adecuarlos con sabiduría al momento para salir avante. Las personas que carecen de esta habilidad tienen que batallar constantemente con las tensiones desagradables, tales como la ansiedad, la tristeza, la irritabilidad y las consecuencias que ellas les contraigan.

3. Motivación. El control de la vida emocional y su subordinación a un objetivo, por lo general el amor, resulta esencial para perseverar a pesar de conflictos, en el alcance de resultados sobresalientes en cualquier área de la vida.

4. Empatía. Es la habilidad de reconocer y comprender las emociones y sentimientos de los demás, es el amor altruista. Las personas empáticas suelen sintonizar con las señales sociales sutiles que indican, que necesitan o que quieren los demás y esta capacidad las hace más aptas para el desempeño de ciertas vocaciones.

5. Habilidades sociales. Es la habilidad para relacionarse adecuadamente con las emociones ajenas, o para interrelacionarse con los demás. Esta habilidad está relacionada con las 4 anteriores. El control de las relaciones se vincula con la popularidad, el liderazgo y la eficacia interpersonal.

\subsection{Inferencias sobre la inteligencia emocional de los millennials}

Prosiguiendo con las conclusiones que marca Goleman, se puede relacionar que las enseñanzas emocionales que se adquieren en el hogar y la escuela durante la infancia moldean los límites emocionales; tornando a cualquiera más apto, o más inepto, en la orientación de los principios que gobiernan su inteligencia emocional. En este sentido, la infancia y la adolescencia constituyen una auténtica oportunidad para asimilar los hábitos emocionales básicos que regirán toda una vida. Por lo anterior se asume que, ya que una generación comparte características cualitativas similares por los diversos factores que influyen en ellos en la época de nacimiento y desarrollo, la inteligencia emocional de los individuos que integran la generación millennial sería más o menos similar. 
En la tabla 1 se encuadra el sentido o la contrariedad de los atributos de los millennials descritos por los tres autores citados, con las competencias que según Goleman circunscribe la inteligencia emocional:

\section{Tabla 1.}

Resumen de los atributos de la Generación millennial por autor.

\begin{tabular}{|c|c|c|c|}
\hline $\begin{array}{c}\text { Principales } \\
\text { Competencias } \\
\text { de la } \\
\text { Inteligencia } \\
\text { Emocional } \\
\text { Según } \\
\text { Goleman }\end{array}$ & $\begin{array}{l}\text { Características } \\
\text { de los } \\
\text { Millennials } \\
\text { según Howe y } \\
\text { Strauss } \\
(2000)\end{array}$ & $\begin{array}{c}\text { Características } \\
\text { de los Millennials } \\
\text { o Generación Me } \\
\text { según Twenge } \\
\text { (2006) }\end{array}$ & $\begin{array}{l}\text { Características de } \\
\text { los Millennials } \\
\text { según Stein } \\
\text { (2013): }\end{array}$ \\
\hline 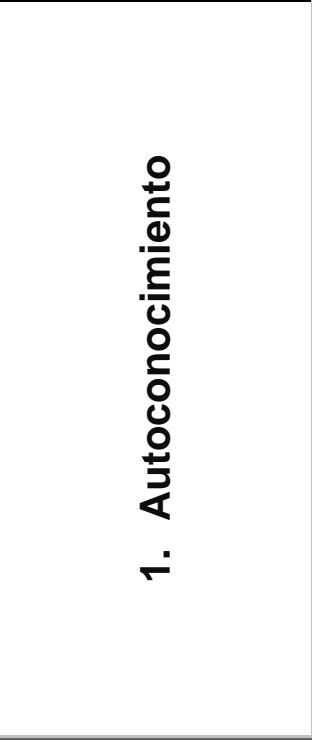 & $\begin{array}{l}\text { Los millennials } \\
\text { sienten que son } \\
\text { especiales }\end{array}$ & $\begin{array}{l}\text { - Utilizan su } \\
\text { vestimenta para } \\
\text { auto-expresarse. } \\
\text { - Se guían por sus } \\
\text { necesidades y } \\
\text { deseos } \\
\text { personales. } \\
\text { - Son } \\
\text { individualistas. } \\
\text { - Se guían por } \\
\text { frases como "sé tú } \\
\text { mismo". } \\
\text { - Demuestran gran } \\
\text { autoestima ya y } \\
\text { seguridad. }\end{array}$ & $\begin{array}{l}\text { - Los padres de los } \\
\text { millenicos } \\
\text { fortalecieron su } \\
\text { autoestima. } \\
\text { - Estas generaciones } \\
\text { piensan antes de } \\
\text { hacer las cosas, no } \\
\text { las hacen por } \\
\text { obligación. } \\
\text { - Son espontáneos, } \\
\text { pragmáticos, y } \\
\text { reservados. }\end{array}$ \\
\hline
\end{tabular}




\begin{tabular}{|c|c|c|c|}
\hline 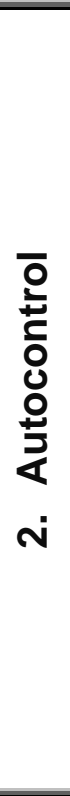 & $\begin{array}{l}\text { Se frustran } \\
\text { rápidamente si } \\
\text { no alcanzan } \\
\text { sus metas. } \\
\text { Esta } \\
\text { generación ha } \\
\text { sido } \\
\text { sobreprotegida. }\end{array}$ & & $\begin{array}{l}\text { - Tardan más tiempo } \\
\text { en ser } \\
\text { independientes. } \\
\text { - Les cuesta } \\
\text { mantener trabajos y } \\
\text { relaciones a largo } \\
\text { plazo por falta de } \\
\text { templanza. } \\
\text { - Se decepcionan } \\
\text { fácilmente cuando } \\
\text { no logran sus metas } \\
\text { o reciben } \\
\text { retroalimentación } \\
\text { favorable. } \\
\text { - Tienen mucho } \\
\text { miedo al fracaso. }\end{array}$ \\
\hline 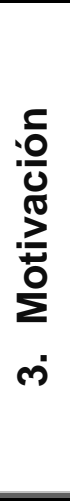 & $\begin{array}{l}\text { - Esta cohorte es } \\
\text { segura y } \\
\text { altamente } \\
\text { optimista. } \\
\text { pienen un } \\
\text { fuerte deseo de } \\
\text { logro } \\
\text { Los Millennials } \\
\text { se sienten } \\
\text { presionados } \\
\end{array}$ & & $\begin{array}{l}\text { - Son soñadores, son } \\
\text { positivos, } \\
\text { optimistas, } \\
\text { idealistas. }\end{array}$ \\
\hline 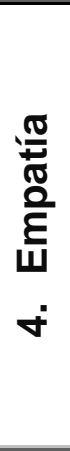 & & $\begin{array}{l}\text { - Desconectados, } \\
\text { son narcisistas, } \\
\text { desconfiados y } \\
\text { ansiosos. } \\
\text { - No se meten en la } \\
\text { vida de los demás. } \\
\text { - No saben respetar } \\
\text { al prójimo o las } \\
\text { normas. }\end{array}$ & $\begin{array}{l}\text { - Personalidad } \\
\text { Narcisista. } \\
\text { - Egocentristas } \\
\text { - No se vinculan cara } \\
\text { a cara, es más } \\
\text { popular en ellos la } \\
\text { convivencia digital. }\end{array}$ \\
\hline
\end{tabular}




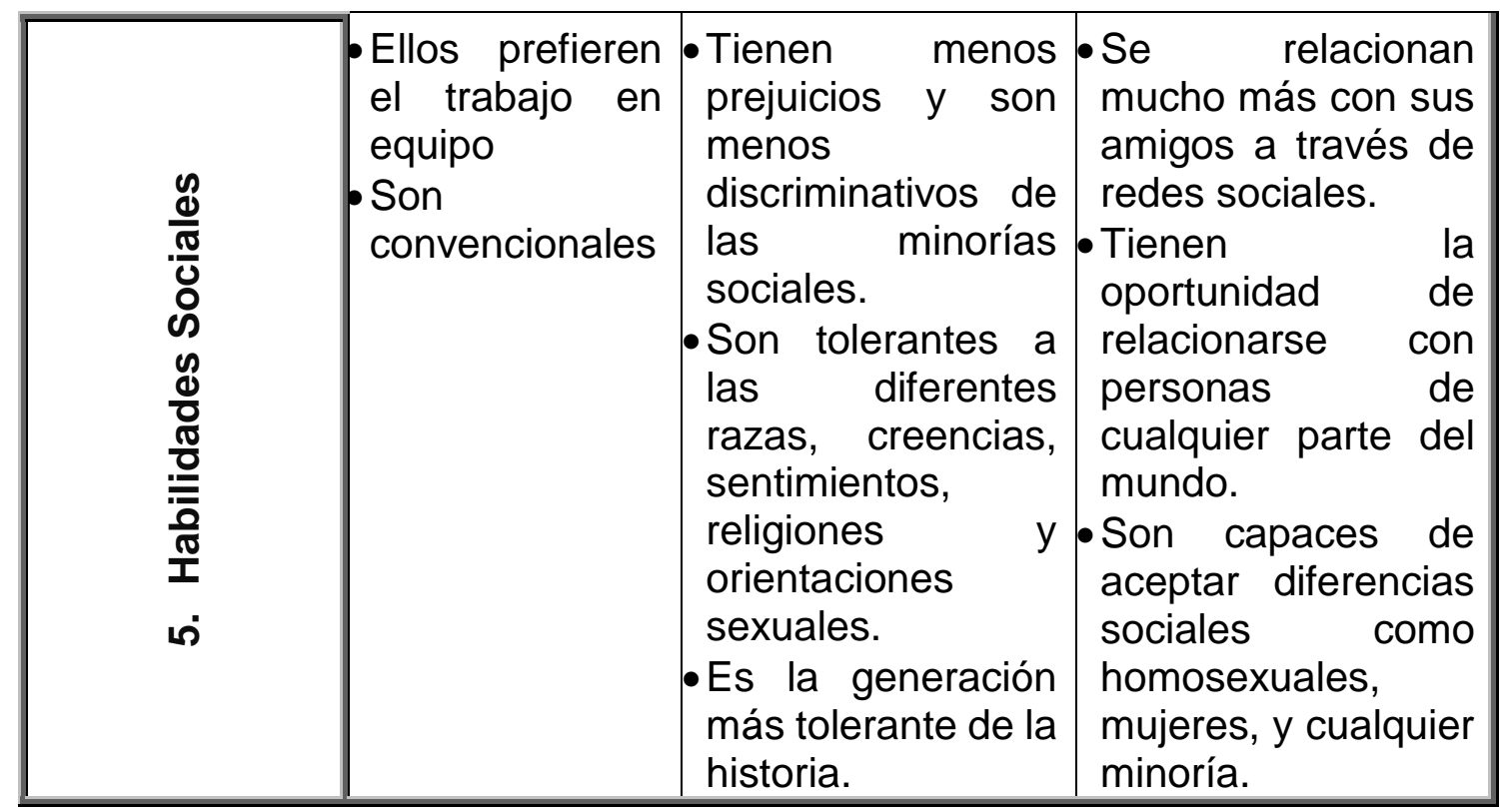

Los individuos que integran la generación millennial fueron poderosamente formados por la educación que recibieron de sus padres, baby boomers, con ánimos de liberarse de las restricciones sociales de la época; los mensajes culturales en las décadas que abarcan esta cohorte, a través de películas, libros o terapeutas, estuvieron basados en fomentar su autoestima impulsando la búsqueda de la felicidad por encima de las normas socio-culturales, coinciden las proyecciones de Howe y Strauss en el año 2000 cuando los millennials apenas alcanzaban la mayoría de edad y los estudios de Twenge y Stein en los años 2006 y 2013. Para dirigir su propia vida lo anterior es bastante beneficioso ya que, los millennials toman decisiones pensando en sí mismos, en lo que desean o buscan; no sienten que necesitan cumplir expectativas grupales o sociales para encajar, están seguros de que son especiales, por lo que esto les permite poseer un buen autoconocimiento, el primer atributo de la inteligencia emocional según Goleman. Ellos comprenden muy bien quiénes son y lo que quieren y así es como rigen su vida.

El excesivo amor y protección que han recibido los millennials de sus padres ha limitado sus capacidades de independencia, tolerancia y templanza; entre otras cosas. Crecieron en un hogar que los hizo creerse especialmente grandes y únicos, acostumbrados a los constantes reconocimientos, por lo que les cuesta mucho trabajo asimilar fracasos. Suelen decepcionarse, frustrarse y deprimirse fácilmente si el universo que les rodea no comparte su grandeza, aseveran las proyecciones de Howe, Strauss y los estudios de Stein. De lo anterior se desprende que no dominan la segunda competencia para la Inteligencia emocional; el autocontrol.

La seguridad y autoestima que fraguaron sus padres en la generación los hizo optimistas, seguros, positivos, soñadores, ellos tienen grandes deseos de logro, además de que la era digital en la que crecieron les facilita resultados en múltiples tareas y amplía sus relaciones sociales. Ellos desean alimentar su sensación de grandeza por el amor propio que se tienen, de tal manera que el éxito personal es la motivación que los mueve para satisfacer esta necesidad. Su objetivo, aunque personal y egoísta, cumple con la tercera competencia de la Inteligencia Emocional. 
Para la penúltima habilidad que conforma la capacidad sentimental los autores Howe y Strauss no mencionan nada al respecto sin embargo, Twenge y Stein coinciden en que el excesivo amor propio que fomentaron los progenitores de la generación, incrementó la personalidad narcisista y su egocentrismo, aunque mencionan que ellos son respetuosos de una gran diversidad de culturas, razas o minorías, esto no necesariamente favorece la descripción de Goleman sobre la relación de empatía con el amor altruista. Los millennials se encuentran tan ensimismados que no pueden realizar sacrificios personales por amor al prójimo.

Las habilidades sociales de la cohorte son, concordantemente por los tres autores mencionados, las mejores en la historia que cualquier otra generación haya tenido. Los millennials son convencionales, son tolerantes, no son prejuiciosos, aceptan las diferencias entre razas, religiones, creencias, sentimientos y orientaciones sexuales, entre otras. Los desarrollos de tecnología que influencian su época les permite relacionarse con personas de cualquier parte del mundo a cualquier hora del día. Ellos prefieren el trabajo en equipo, son pragmáticos, por lo que en ésta última competencia de la inteligencia emocional, son los mejores.

\section{Conclusiones y recomendaciones}

La grandiosa generación nacida entre los años 1980 y 2004 representa hoy en día un 31.5\% de la poblacional a nivel mundial (Tecnohotel, 2018) esto, motiva a prestar atención a sus cualidades sólidas y endebles, ellos son los padres que educarán a la futura sociedad, ellos son los líderes actuales y futuros, de manera que el bienestar global depende y dependerá de ellos.

La peculiar educación, comparada con otras generaciones, que recibieron de sus padres los millennials y las influencias de los excelsos y actuales avances tecnológicos, favorecieron la concepción en ellos de tres de los cinco atributos que circunscribe la inteligencia emocional, el autoconocimiento, la motivación y las habilidades sociales. Ellos aprendieron a conocerse bien, dado que fueron incitados por diversos medios a ser ellos mismos. Han aprendido a identificar sus deseos, emociones o sentimientos para tomar sus decisiones, lo que es bueno para la comprensión de sí mismo y la dirección de la vida hacía las propias metas y sueños. Fueron tatuados con la frase "eres especial" y la adicción a la dopamina que genera la sensación de grandeza los motiva a buscar éxito. La tecnología y la apertura al cambio favorece en ellos la socialización de sobremanera, aceptan cualquier diferencia cultural, racial u orientación sexual sin problemas, lo que les permite un buen desempeño de actividades grupales. Sin embargo, su alta autoestima llega a niveles del narcisismo, considerado así por Twenge y Stain, lo que no es bueno para el control de las emociones, es difícil para ellos aceptar derrotas o fracasos. Las emociones como el enfado, la tristeza y la ansiedad tienen una función de supervivencia en el individuo, pero 
la falta de autorregulación de ellas impide el gobierno de la vida propia y el aumento de posibles riesgos, aunque se puedan identificar es necesario controlarlas. Finalmente, su narcisismo también genera falta de empatía, no existe en ellos el amor altruista, solo el amor propio, y ¿cómo relacionarse en una sociedad si no se ayudan unos a otros? El ser humano no es autosuficiente.

Si se mide la inteligencia emocional en forma proporcional a las 5 competencias que señala Goleman y a cada una se le atribuye un $20 \%$ de valor, los Millennials son el $60 \%$ hábiles con sus sentimientos, lo que sugiere que tienen la mayoría de las habilidades, sin embargo, como anteriormente se menciona, esta sociedad debe de llenar los vacíos que la educación parental, heredada en ellos, generó.

Las Instituciones laborales y educativas deben involucrarse activamente y evolucionar para incluir en sus capacitaciones y temarios de estudio la impartición de competencias, principalmente estas que conforman la inteligencia emocional. Son estos organismos los que contribuyen a la integración de una sociedad afable, por lo tanto son los que deben aprovechar las sólidas habilidades que poseen al respecto del autoconocimiento, la motivación y sus habilidades sociales así como coadyuvar a fortalecer las endebles, empatía y autocontrol, para la mejora de la humanidad de manera que la futura generación, llamada centennial o generación z, herede una inteligencia emocional integral y los millennials serán quienes contribuyan a ello, además de favorecer a través de sus diversas responsabilidades entre otras cosas al desarrollo sustentable, a bajar tasas de corrupción, a multiplicar oportunidades de trabajo, a aumentar niveles educativos, etc.

\section{Agradecimientos:}

Es significativo para nosotros expresar nuestro sincero agradecimiento por la valiosa orientación y experiencia profesional compartida de nuestra mentora la Dra. Luz Helena Sanin Aguirre ya que sin su ayuda el logro de nuestro trabajo no se hubiera completado satisfactoriamente. 


\section{Referencias:}

Cambridge University Press. (s.f.). Cambridge Dictionary. Recuperado el 01 de Julio de 2019, de Millennials: https://dictionary.cambridge.org/es/diccionario/ingles/millennial

Carro, G. (24 de Enero de 2020). Depresión en los jóvenes: los trastornos mentales aumentan en cada generación. GQ, 1. Recuperado el 2020, de Juventud Deprimida: los transtornos mentales aumentan cada generación: https://www.revistagq.com/la-buenavida/articulos/incremento-depresion-trastornos-mentales-generacion-z-millennials/31610

Goleman, D. (1995). Inteligencia Emocional. Barcelona, España: Kairós.

Google. (2021). Google Trends. Obtenido de https://trends.google.es/trends/?geo=ES

Howe, N., y Strauss, W. (1987). Generations The History of America's Future, 1584 To 2069. Nueva York, Broadway, Estados Unidos: Harper Parennial. Recuperado el 07 de Julio de 2019, https://archive.org/details/GenerationsTheHistoryOfAmericasFuture1584To2069ByWilliam StraussNeilHowe/page/n31

Howe, N., y Strauss, W. (2000). Millennials Rising: The Next Great Generation. Nueva York: Knopf Doubleday Publishing Group.

Monaco, M., y Martin, M. (Julio de 2007). The Millennial Student: A New Generation of Learners. Athletic Training Education Journal , Apr-Jun, 42-46. Recuperado el 02 de Junio de 2019, de https://www.natajournals.org/doi/pdf/10.4085/1947-380X-2.2.42

Pérez, J., y Gardey, A. (2019). Definicion.de. Recuperado el 01 de Julio de 2019, de Definición de Millennials: https://definicion.de/millennial/

Ruíz, D. J. (Julio de 2017). Millennials and Social Networks: Strategies for Effective Brand Communication. Miguel Hernández Communication Journal, 8, 347-367. Recuperado el 06 de Julio de 2019, de Miguel Hernández Communication Journal No 8, pp 347 to 367 Universidad Miguel Hernández: http://dspace.umh.es/bitstream/11000/5191/1/196-867-1PB.pdf

Salovey, P., y Mayer, J. D. (1990). Emotional Intelligence. Obtenido de http://citeseerx.ist.psu.edu/viewdoc/download?doi=10.1.1.385.4383\&rep=rep1\&type=pdf

Stein, J. (20 de Mayo de 2013). Millennials: The me me me Generation . Time, Mayo, 1. Obtenido de http://time.com/247/millennials-the-me-me-me-generation/ 
Tecnohotel. (27 de Agosto de 2018). La Generación Z superará en número a los Millennials . Tecnohotel. Recuperado el 02 de Abril de 2020, de https://www.tecnohotelnews.com/2018/08/27/generacion-z-superara-millennials-2019/

Twenge, J. M. (11 de Abril de 2006). Generation Me. Recuperado el 07 de Julio de 2019, de Simon

\& Schuster: https://www.simonandschuster.com/books/Generation-Me-Revised-andUpdated/Jean-M-Twenge/9781476755564

Cómo citar este artículo:

Torres Ortega, E. A., Cabrera Ramos, C. ., Flores Morales, C. R. ., \& De La Rosa Flores, C. C. . (2021). POTENCIALIDADES QUE OFRECE LA PECULIAR INTELIGENCIA EMOCIONAL DE LOS MILLENNIALS. Revista De Investigación Académica Sin Frontera: División De Ciencias Económicas Y Sociales, (35). https://doi.org/10.46589/rdiasf.vi35.362

https://revistainvestigacionacademicasinfrontera.unison.mx/index.php/RDIASF/article/view/362
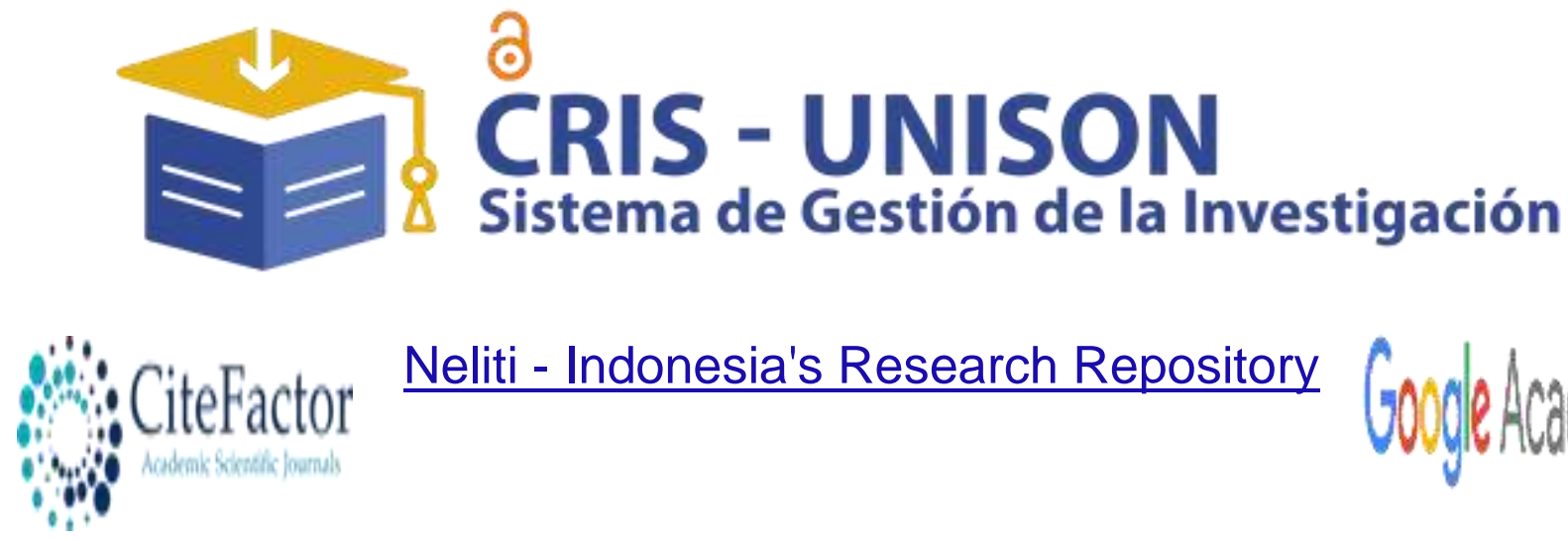

\section{Neliti - Indonesia's Research Repository}

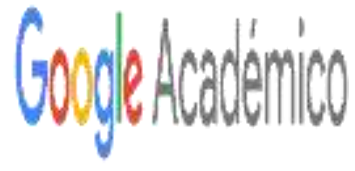

○ Dialnet

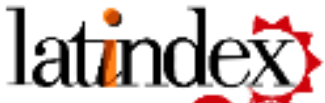

catálogdi2.0

(1)

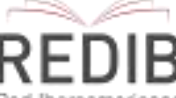

REDIB

Fied iberoamanicana

\section{Signatory of}

DORA

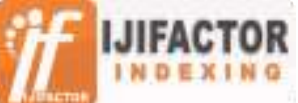

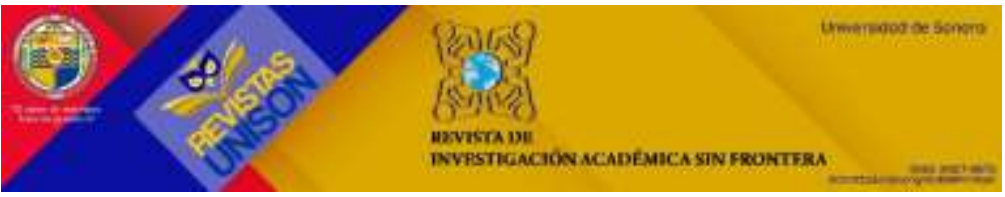

